\title{
Emergency Care
}

National Cancer Institute

\section{Source}

National Cancer Institute. Emergency Care. NCI Thesaurus. Code C52641.

Care necessary to treat acute pain, infection, bleeding, or trauma. 